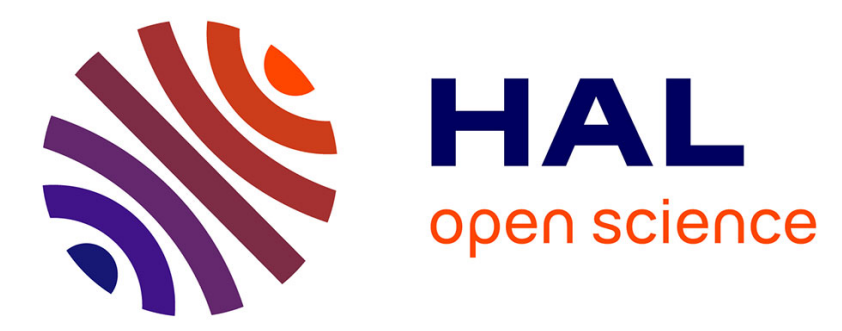

\title{
Performance of stool cultures before and after a 3-day hospitalization: fewer cultures, better for patients and for money
}

Rémi Le Guern, Caroline Loïez, Bruno Grandbastien, René Courcol, Frederic Wallet

\section{To cite this version:}

Rémi Le Guern, Caroline Loïez, Bruno Grandbastien, René Courcol, Frederic Wallet. Performance of stool cultures before and after a 3-day hospitalization: fewer cultures, better for patients and for money. Diagnostic Microbiology and Infectious Disease, 2013, 77 (1), pp.5-7. 10.1016/j.diagmicrobio.2013.06.002 . hal-02566192

\section{HAL Id: hal-02566192 \\ https://hal.science/hal-02566192}

Submitted on 14 May 2020

HAL is a multi-disciplinary open access archive for the deposit and dissemination of scientific research documents, whether they are published or not. The documents may come from teaching and research institutions in France or abroad, or from public or private research centers.
L'archive ouverte pluridisciplinaire HAL, est destinée au dépôt et à la diffusion de documents scientifiques de niveau recherche, publiés ou non, émanant des établissements d'enseignement et de recherche français ou étrangers, des laboratoires publics ou privés. 
TITLE: Performance of stool cultures before and after a 3-day hospitalization: fewer cultures, better for patients and for money

AUTHORS: Rémi Le Guern ${ }^{\mathrm{a}}$, Caroline Loïez ${ }^{\mathrm{a}}$, Bruno Grandbastien ${ }^{\mathrm{b}, \mathrm{c}}$, René Courcol $^{\mathrm{a}, \mathrm{c}}$ and Frédéric Wallet ${ }^{\mathrm{a}}$

\section{INSTITUTIONS:}

${ }^{a}$ Institut de Microbiologie, CHU Lille, France

${ }^{\mathrm{b}}$ Service de Gestion du Risque Infectieux, des Vigilances et d'Infectiologie, CHU Lille, France

${ }^{\mathrm{c}}$ Univ Lille Nord de France, F-59019 Lille, France

KEYWORDS: rejection criteria, 3-day rule, nosocomial outbreak, bacterial diarrhea, length of hospitalization, cost savings

RUNNING TITLE: Stool Culture and Cost-Savings

CORRESPONDING AUTHOR: F. Wallet M. D.

Centre de Biologie-Pathologie

Institut de Microbiologie

Bld du Pr Leclercq, F-59037 - Lille Cedex, France

Telephone number $:+33-320.445 .480$

Fax number : +33-320.444.895

e-mail : frederic.wallet@chru-lille.fr 


\begin{abstract}
We evaluated retrospectively the yield of stool culture (SC) depending on the length of hospitalization, and we characterized the patients missed by the 3-day rejection rule. SC detects bacterial enteric pathogens (Campylobacter spp., Salmonella enterica, Yersinia spp., Shigella spp.). During this 5-year study period, 13,039 SCs were requested, and 376 were positive (2.9\%). The yield of SC dropped from $11.7 \%$ before 3 days of hospitalization to $0.7 \%$ after 3 days in children and $4.3 \%$ to $0.3 \%$ in adults. Finally, only 13 clinically relevant cases ( $0.2 \%$ of SC prescribed after 3 days) were undiagnosed by strict application of the 3 -day rule. In conclusion, rejection of SC prescribed after 3 days of hospitalization allows to reduce workload by $37.8 \%$ for children and $65.7 \%$ for adults, representing a cost of $€ 12,500$ $(\$ 16,250)$ per year in our hospital.
\end{abstract}




\section{Introduction}

Stool culture (SC) are prescribed to detect bacterial enteric pathogens (Campylobacter spp., Salmonella enterica, Yersinia enterocolitica, Shigella spp.), which are frequently community-acquired. Therefore, the yield of SC is low in hospitalized patients (2.6-6.1\%) (Fan et al., 1993)'(Rohner et al., 1997), especially after 3 days of hospitalization (0.5\%) (Bauer et al., 2001). Thus, some laboratories reject SC submitted after 3 days of hospitalisation (“3-day rule”), considering Clostridium difficile is the major microorganism responsible for nosocomial bacterial diarrhoea (Versalovic, 2011).

In 2001, a European study group (Bauer et al., 2001) modified this 3-day rejection rule to propose exceptions for high risk patients in adult population (neutropenic, HIV-positive, or age $>65$ years with comorbidities). These guidelines were validated in Freiburg Hospital (Germany): the global yield of stool culture was $1.0 \%$ on 3416 samples, and $82.5 \%$ of the SC were sent after 3 days of hospitalization. This particular population may not be representative of all European laboratories. In Lisbon (Portugal) the global yield of SC was 9\% on 853 samples and $64.6 \%$ of the stool cultures were sent after 3 days of hospitalisation (Hanscheid et al., 2002). The guidelines validated for adults by Bauer et al. were later extended to children in 2007 (Seyler et al., 2007). In this paediatric population from Oxford, the global yield of SC was $1.9 \%$ on 5262 samples, and $29 \%$ of the stool cultures were sent after 3 days of hospitalization.

The first objective of this study is to evaluate retrospectively in Lille University Hospital (France) the yield of SC depending on the length of hospitalization, and to characterize the patients missed by the 3-day rejection rule. It seems necessary to evaluate the application of rejection criteria separately on children (age $<16$ years old), because the 
epidemiology of infectious diarrhoea differs markedly between adults and children (Pfeiffer et al., 2012). The second aim is to evaluate the potential savings for the laboratory.

\section{Material and Methods}

Stool cultures requested from January 2007 to December 2011 in Lille University Hospital were included retrospectively in this study. Follow-up cultures after a positive result were excluded. For Campylobacter spp. detection, all specimens were streaked onto Karmali medium (bioMérieux, Marcy l'Etoile, France) without microfiltration and incubated at $37^{\circ} \mathrm{C}$ in a microaerophilic atmosphere (85\% nitrogen, $10 \%$ carbon dioxide, 5\% oxygen) for 48 hours. To detect Salmonella enterica and Shigella spp., all specimen were streaked onto Hektoen medium (bioMérieux, Marcy l'Etoile, France) and incubated at $37^{\circ} \mathrm{C}$ in air for 24 hours. To enhance the recovery of Salmonella enterica, we used a Selenite F broth (bioMérieux, Marcy l'Etoile, France), which was subcultured onto Hektoen after 18 hours of incubation at $37^{\circ} \mathrm{C}$. Yersinia enterocolitica were detected using Schiemann-CIN medium (bioMérieux, Marcy l'Etoile, France) after an incubation of 24 hours at $28^{\circ} \mathrm{C}$ in air.

To identify bacterial enteric pathogens, we used conventional biochemical techniques from January 2007 to September 2009. For Salmonella enterica and Shigella spp., suspicious colonies on Hektoen were screened for urease activity and streaked onto Kligler agar. Depending on the results of these tests, we continued with VITEK 2 GN (bioMérieux, Marcy 1'Etoile, France) or with Shigella antisera (Bio-Rad, Marnes la Coquette, France). Campylobacter spp. were identified by API Campy (bioMérieux, Marcy l'Etoile, France), and Yersinia enterocolitica using the VITEK 2 GN. From October 2009 to December 2011, we used MALDI-TOF mass spectrometry (Microflex; Bruker Daltonics, Wissembourg, France). 
Shigella strains were still identified by seroagglutination since MALDI-TOF cannot identify this specific bacterial genus.

We estimated the average stool culture would cost $7.98 €$ for our laboratory. This global cost can be decomposed into culture media (1.53€), automated specimen inoculation (1.04€), bacterial identification $(0.41 €)$ and technical personnel (5.00€).

Statistical analysis was performed with SPSS 20.0. Mann-Whitney test was used to compare the length of hospitalization for children versus adults. Chi-squared test was used to compare the yield of SC, and this analysis was also stratified by hospitalization length. $P$ values of less than 0.05 were considered to indicate a statistically significant difference. 


\section{Results}

During this 5-year study period, 13,039 SC were requested, corresponding to 10,635 patients (including 2,238 children). 376 were positive (2.9\%): 239 SC for Campylobacter spp. (63.6\% of the positive stool cultures), 111 for Salmonella enterica (29.5\%), 18 for Shigella spp. (4.8\%), and 8 for Yersinia enterocolitica $(2.1 \%)$.

The global yield of SC was higher for children (7.6\%) than for adults (1.7\%) $(\mathrm{p}<0.001)$ (Table 1). Only $37.8 \%$ of SC were prescribed after 3 days of hospitalization for children compared to $65.7 \%$ for adults $(\mathrm{p}<0.001)$. As the yield of SC falls sharply when the length of hospitalization increases, we performed a stratified analysis based on 4 categories of hospitalization length (Figure 1). At Day 0, the yield of SC was $18.8 \%$ for children and $7.9 \%$ for adults $(\mathrm{p}<0.001)$. After Day 3, no significant difference was found between the yield of $\mathrm{SC}$ in children $(0.7 \%)$ versus adults $(0.3 \%)(\mathrm{p}=0.09)$.

Strict application of the 3 day-rule rejection criteria would have led to miss 7 cases of bacterial enteric pathogens for children (3.5\% of all positive SC) and 23 cases for adults (13.0\% of all positive SC) (Table 2). Among these 30 missed cases, 4 were asymptomatic carriers, 4 had non-diarrheal manifestations of enteric infection (SC prescribed after bacteraemia or abscess due to enteric pathogens), and 9 were hospitalized patients with a community acquired diarrhoea at Day 0 but the first SC was prescribed after more than 3 days of hospitalization. Only 13 of the 30 positive SC prescribed after 3 days of hospitalization would have been relevant ( 4 children and 9 adults), representing $0.2 \%$ of all the SC prescribed for nosocomial diarrhoea.

Patients suffering from nosocomial diarrhoea often received chemotherapy during the preceding weeks (7 of the 13 clinically relevant cases) but only 2 of them had severe 
neutropenia (absolute neutrophil count $<0.5 \times 10^{9} / \mathrm{L}$ ). Four patients had haematological malignancies, 2 had solid tumours and 1 was treated with methotrexate for Crohn's disease.

The yield of SC was higher during warmer months: $4.0 \%$ from May to September (with a maximum of $5.0 \%$ in July) against $2.0 \%$ from October to April (with a minimum of $1.7 \%$ in February). The number of SC prescribed per month remained stable, regardless of the season $($ mean $=217$, standard deviation $=18)$.

Using the 3-day rule, $7,830 \mathrm{SC}$ would have been rejected $(60.0 \%$ of all the SC received). The potential savings for the laboratory would have been about $12,500 €$ per year (culture media 2,400€, automated specimen inoculation $1,630 €$, bacterial identification $640 €$ and technical personnel 7,830€). 


\section{Discussion}

Even if the yield of SC prescribed after 3 days of hospitalization was low $(0.7 \%$ for children and $0.3 \%$ for adults), 13 clinically relevant cases would have been missed by the strict application of the 3-day rule (4 children and 9 adults). Among these 9 adult cases of nosocomial diarrhoea undiagnosed, only 2 would have been detected by the application of Bauer guidelines ( 1 had age > 65 years associated with comorbidities, and 1 had severe neutropenia).

Interestingly, we found that 7 patients out the 13 clinically relevant cases of nosocomial diarrhoea received chemotherapy. Asymptomatic colonization with enteropathogenic bacteria can lead to invasive disease triggered by cancer chemotherapy, as previously reported for Salmonella (Delaloye et al., 2004), probably due to mucositis and immunosuppression. In our study, 4 patients developed nosocomial Campylobacter diarrhoea (2 C. coli, 2 C. jejuni) and 3 developed Salmonella enterica diarrhoea after receiving chemotherapy.

After 3 days of hospitalization, there was no significant difference between the yield of SC in children compared to adults. Although children seem particularly susceptible to develop community-acquired diarrhoea, that does not justify the research of enteropathogenic bacteria after 3 days of hospitalization. Globally, SC did not add much value to the diagnosis of nosocomial diarrhoea, except for patients under cancer chemotherapy.

The higher number of positive SC cases detected in warm months (May to September) can be explained by the epidemiology of Campylobacter and Salmonella infections (representing $93 \%$ of our positive cases). Indeed, the increase of ambient temperature is known to be associated with Campylobacter (Nichols et al., 2012) or Salmonella (Ravel et al., 2010) infections. However, the number of SC prescribed per month remained stable during 
the year. This may be explained by the winter seasonality of viral gastroenteritis (Mounts et al., 2000), contrasting with the summer seasonality of most bacterial enteric infections. Physicians prescribe SC in case of diarrhoea, not knowing if the aetiological agent is a bacteria, a parasite or a virus.

The introduction of rejection criteria for SC can potentially delay the diagnosis of nosocomial outbreaks due to bacterial enteric pathogens (Bruins et al., 2003). These outbreaks are very rare nowadays, thanks to higher standards of hygiene. Actually, no cluster of nosocomial cases has been identified during the 5 years covered by this study.

In conclusion, rejection of SC prescribed after 3 days of hospitalization allows to reduce workload by $37.8 \%$ for children and $65.7 \%$ for adults, representing cost-savings of $12,500 €(16,250 \$)$ per year. Few cases of clinically relevant enteric infections are missed, but even the exception criteria proposed by Bauer et al. do not identify all of these cases. Patients under cancer chemotherapy seem particularly at risk to develop nosocomial diarrhoea caused by enteropathogenic bacteria. Overall, this study highlights the importance of communication between clinical microbiologists and physicians before the prescription of SC for patients suffering from nosocomial diarrhoea.

\section{Conflict of interest statement}

None declared.

\section{Funding sources}

None. 


\section{References}

Bauer, TM, Lalvani, A, Fehrenbach, J, Steffen, I, Aponte, JJ, Segovia, R, Vila, J, Philippczik, G, Steinbruckner, B, Frei, R, Bowler, I, \& Kist, M (2001) Derivation and validation of guidelines for stool cultures for enteropathogenic bacteria other than Clostridium difficile in hospitalized adults. JAMA, 285, 313-319.

Bruins, MJ, Fernandes, TMA, Ruijs, G, Wolfhagen, M, van Rijn-van Berkel, JM, Schenk, BE, \& van Duynhoven, Y (2003) Detection of a nosocomial outbreak of salmonellosis may be delayed by application of a protocol for rejection of stool cultures. $J$ Hosp Infect, 54, 93-98.

Delaloye, J, Merlani, G, Petignat, C, Wenger, A, Zaman, K, Monnerat, C, Matzinger, O, Beck Popovic, M, Vuichard, P, Ketterer, N, \& Tarr, PE (2004) Nosocomial nontyphoidal salmonellosis after antineoplastic chemotherapy: reactivation of asymptomatic colonization? Eur J Clin Microbiol Infect Dis, 23, 751-758.

Fan, K, Morris, AJ, \& Reller, LB (1993) Application of rejection criteria for stool cultures for bacterial enteric pathogens. J Clin Microbiol, 31, 2233-2235.

Hanscheid, T, Cristino, JM, \& Salgado, MJ (2002) Feasibility of introducing rejection criteria for stool cultures in a teaching hospital in Portugal. Clin Microbiol Infect, 8, 118-121.

Mounts, AW, Ando, T, Koopmans, M, Bresee, JS, Noel, J, \& Glass, RI (2000) Cold weather seasonality of gastroenteritis associated with Norwalk-like viruses. J Infect Dis, 181 Suppl 2, S284-287.

Nichols, GL, Richardson, JF, Sheppard, SK, Lane, C, \& Sarran, C (2012) Campylobacter epidemiology: a descriptive study reviewing 1 million cases in England and Wales between 1989 and 2011. BMJ Open, 2. 
Pfeiffer, ML, DuPont, HL, \& Ochoa, TJ (2012) The patient presenting with acute dysentery-a systematic review. J Infect, 64, 374-386.

Ravel, A, Smolina, E, Sargeant, JM, Cook, A, Marshall, B, Fleury, MD, \& Pollari, F (2010) Seasonality in human salmonellosis: assessment of human activities and chicken contamination as driving factors. Foodborne Pathog Dis, 7, 785-794.

Rohner, P, Pittet, D, Pepey, B, Nije-Kinge, T, \& Auckenthaler, R (1997) Etiological agents of infectious diarrhea: implications for requests for microbial culture. J Clin Microbiol, $35,1427-1432$.

Seyler, L, Lalvani, A, Collins, L, Goddard, L, \& Bowler, ICJW (2007) Safety and cost savings of an improved three-day rule for stool culture in hospitalised children and adults. J Hosp Infect, 67, 121-126.

Versalovic, J (2011) Manual of Clinical Microbiology (10th ed.). Washington, DC: ASM Press. 


\section{Tables and Figures legends}

Table 1. Characteristics of the study population (children versus adults)

Table 2. Epidemiology of the bacterial enteric pathogens detected after 3 days of hospitalization

C.: Campylobacter, S.: Salmonella, Y.: Yersinia

Figure 1. Stool culture yield stratified on the length of hospitalization (children versus adults) ${ }^{*}: \mathrm{p}<0.001, \mathrm{NS}$ : non significant 
Table 1. Characteristics of the study population (children versus adults)

\begin{tabular}{|c|c|c|c|c|c|}
\hline \multirow[b]{2}{*}{ Stool Culture (SC) } & \multicolumn{2}{|c|}{ Children } & \multicolumn{2}{|c|}{ Adults } & \multirow[b]{2}{*}{$\begin{array}{c}P- \\
\text { value }\end{array}$} \\
\hline & Positive & Negative & Positive & Negative & \\
\hline $\begin{array}{l}\text { Total Number of SC } \\
\qquad(\%)\end{array}$ & $\begin{array}{c}199 \\
(7.6 \%)\end{array}$ & $\begin{array}{c}2,431 \\
(92.4 \%)\end{array}$ & $\begin{array}{c}177 \\
(1.7 \%)\end{array}$ & $\begin{array}{c}10,232 \\
(98.3 \%)\end{array}$ & $<0.001$ \\
\hline $\begin{array}{c}\text { SC sent before } 3 \text { days } \\
(\%)\end{array}$ & $\begin{array}{c}192 \\
(11.7 \%)\end{array}$ & $\begin{array}{c}1,443 \\
(88.3 \%)\end{array}$ & $\begin{array}{c}154 \\
(4.3 \%)\end{array}$ & $\begin{array}{c}3,420 \\
(95.7 \%)\end{array}$ & $<0.001$ \\
\hline $\begin{array}{c}\text { SC sent after } 3 \text { days } \\
(\%)\end{array}$ & $\begin{array}{c}7 \\
(0.7 \%)\end{array}$ & $\begin{array}{c}988 \\
(99.3 \%)\end{array}$ & $\begin{array}{c}23 \\
(0.3 \%)\end{array}$ & $\begin{array}{c}6,812 \\
(99.7 \%)\end{array}$ & 0.09 \\
\hline $\begin{array}{l}\text { Median length of hospitalization } \\
\text { (days) }\end{array}$ & 0 & 2 & 1 & 8 & $<0.001$ \\
\hline $\begin{array}{l}\text { Age (mean years } \pm \\
\text { standard deviation) }\end{array}$ & $\begin{array}{c}4.84 \\
( \pm 4.62)\end{array}$ & $\begin{array}{c}3.44 \\
( \pm 4.86)\end{array}$ & $\begin{array}{c}43.89 \\
( \pm 20.49)\end{array}$ & $\begin{array}{c}60.07 \\
( \pm 18.95)\end{array}$ & \\
\hline Sex Ratio & 1,26 & 1,21 & 1,36 & 1,14 & 0.22 \\
\hline
\end{tabular}


Table 2. Epidemiology of the bacterial enteric pathogens detected after 3 days of hospitalization

\begin{tabular}{|c|c|c|}
\hline Epidemiology & n (\%) & Bacterial species \\
\hline \multicolumn{3}{|l|}{ Children } \\
\hline Community acquired diarrhoea & $1(14 \%)$ & $1 C$. jejuni \\
\hline Nosocomial diarrhoea (with chemotherapy) & $2(29 \%)$ & 1 C. coli, 1 S. enterica \\
\hline Nosocomial diarrhoea (without chemotherapy) & $2(29 \%)$ & 1 C. coli, 1 S. enterica \\
\hline Non-diarrheal manifestation of enteric infection & $1(14 \%)$ & 1 S. enterica \\
\hline Asymptomatic carrier & $1(14 \%)$ & $1 C$. jejuni \\
\hline Total & $7(100 \%)$ & $\begin{array}{c}2 \text { C. jejuni, } 2 \text { C. coli, } \\
3 \text { S. enterica }\end{array}$ \\
\hline \multicolumn{3}{|l|}{ Adults } \\
\hline Community acquired diarrhoea & $8(35 \%)$ & 1 C. jejuni, 5 C. coli, 2 S. enterica \\
\hline Nosocomial diarrhoea (with chemotherapy) & $5(22 \%)$ & 2 C. jejuni, 1 C. coli, 2 S. enterica \\
\hline Nosocomial diarrhoea (without chemotherapy) & $4(17 \%)$ & 2 C. jejuni, $1 S$. enterica, $1 Y$. enterocolitica \\
\hline Non-diarrheal manifestation of enteric infection & $3(13 \%)$ & 3 S. enterica \\
\hline Asymptomatic carrier & $3(13 \%)$ & 1 C. jejuni, 1 C. coli, 1 S. enterica \\
\hline Total & $23(100 \%)$ & $\begin{array}{c}6 C . \text { jejuni, } 7 \text { C. coli, } \\
9 \text { S. enterica }, 1 Y . \text { enterocolitica }\end{array}$ \\
\hline
\end{tabular}

C.: Campylobacter, S.: Salmonella, Y.: Yersinia 